\title{
Networks of international co-authorship in journal articles about Antarctic research, 1998-2015
}

\author{
Duckhee Jang, ${ }^{1}$ (1) Soogwan Doh ${ }^{2}$ (1) \& Yongjin $\mathrm{Choi}^{3}$ (1) \\ ${ }^{1}$ Ocean Policy Institute, Korea Institute of Ocean Science and Technology, Busan, South Korea; \\ ${ }^{2}$ Department of Public Administration, University of Ulsan, Ulsan, South Korea; \\ ${ }^{3}$ Department of Public Administration and Policy, Rockefeller College of Public Affairs and Policy, University at Albany, State University of New York, \\ Albany, NY, USA
}

\begin{abstract}
This study seeks insight into the social structure of Antarctic research from 1998 to 2015 by examining peer-reviewed journal articles listed in the Science Citation Index of the Web of Science database. This study identifies leading countries in peer-reviewed journal article output and applies social network analysis methods to identify countries where authors are collaborating with those affiliated with organizations in different countries. The results show that the number of publications on Antarctica and the proportion of international research collaboration increased from 23.0 to $33.2 \%$ during the period of time being considered. The number of articles published by authors affiliated with institutions in emerging countries such as China, Turkey, Brazil and South Korea rose, whereas the proportion of articles published by authors affiliated with institutions in the United States decreased. The largest proportion of academic publications pertaining to Antarctic research was within the natural sciences. Within this broad field, the majority of publications fell within Earth and related environmental sciences and the biological sciences. Social network analysis shows that Antarctic research moved towards a network, in which researchers are internationally more connected than ever before, with countries such as the United States, the United Kingdom, Germany, France and Australia in central positions. Sweden, Belgium and the Netherlands did not account for a high percentage of academic contributions but were still notable for their multinational collaborative research.
\end{abstract}

\section{Introduction}

The political, economic and social importance of Antarctica and international competition over its resources have been escalating (Geissler \& Kelly 2016; Jang et al. 2016) The growing recognition of Antarctica's role in environmental issues such as climate change is one of the reasons for the recent growth of Antarctic science (O'Reilly et al. 2012). Some emerging countries, such as China and India, as well as Western countries, such as the United States, Canada and European countries, have expanded their research activities and investments in Antarctica at a rapid pace.

The Antarctic is known as an area that requires intensive research collaboration on the account of the region's harsh conditions and remoteness, resulting in complicated logistics and high cost of access (Lüdecke 2003; Erb 2011). Intergovernmental research programmes and organizations, such as the IPY and SCAR, have provided the basis for promoting

\section{Keywords}

Antarctica; polar; research cooperation; bibliometrics; social network analysis; Web of Science (WoS)

\section{Correspondence}

Soogwan Doh, Department of Public Administration, University of Ulsan, 93 Daehak-ro, Nam-gu, Ulsan 44610, South Korea. E-mail: doh.soogwan@gmail.com

\section{Abbreviations \\ IPY: International Polar Year OECD: Organisation for Economic Co-operation and Development SCAR: Scientific Committee on Antarctic Research \\ SNA: social network analysis WoS: Web of Science database, Clarivate Analytics}

international and inter-organizational interactions and sharing of data and information to solve complex problems in Antarctica (Lüdecke 2003; Summerhayes 2008).

Has scientific collaboration in Antarctic research increased, as international research programmes aimed? If so, what does the social structure of Antarctic science look like? Which countries are influential in the network of scientific collaboration? Despite efforts to connect scientists, there has been very little research documenting the collaborative structure of Antarctic research.

This paper contributes to filling this gap by drawing on SNA to analyse journal article output as found in the WoS database. Over the past few decades, there have been considerable theoretical and methodological developments in studying scientific collaboration with SNA in the social and natural sciences (Katz 1994; Newman 2001; Barabási et al. 2002). Given growing international efforts to encourage collaborations in the scientific community, we believe that the application of SNA to collaboratively 
produced journal articles will improve our understanding of the social structure of Antarctic research.

The following section reviews the research background of scientific studies of Antarctica and explores the importance of international research collaboration in the region. The third section describes the data and methods used in this study, and the fourth section presents the research findings and discusses them. We conclude with the implications of the findings on Antarctic research.

\section{Research background}

Previous studies suggest two main reasons why Antarctic research is essential. First, the Antarctic continent and the regions surrounding the continent play an influential role in the Earth's natural systems: phenomena that take place in the Antarctic have enormous impacts throughout the world, including on human society. For example, the potential demise of the West Antarctic Ice Sheet has great societal importance because of the rise in sea level that would ensue from it. Like the Arctic, the Antarctic Peninsula region has undergone tremendous warming in the past 60-65 years compared with the rest of the planet, and ecosystem change is occurring there at a rapid pace that demands investigation to shed light on the ongoing or future effects of climate change around the world. Second, Antarctica is a so-called natural laboratory that permits the study of organisms, materials (such as meteorites) and natural phenomena (such as solar wind), which are absent or difficult to observe in other regions (Fogg 1992). Some resources in Antarctica, such as oil and mineral deposits, are expected to contribute to scientific and technological developments and to produce considerable economic benefits.

Multiple areas of scholarship have converged in Antarctic research to overcome the extreme environmental conditions and to better understand Antarctic phenomena, which require interdisciplinary knowledge and observation because of their size and complexity (Fogg 1992; Heggie 2016). Research in Antarctica not only requires cutting-edge technology to overcome environmental challenges but also depends significantly on expertise from diverse backgrounds.

Large funds are also needed. In the early 1900s, the greatest obstacle to Antarctic research was the difficulty in securing research funding for research activities (Lüdecke 2003). Germany and the United Kingdom collaborated because they had a shared interest in securing largescale funding for the research vessels (e.g., icebreakers) required to explore Antarctica (Lüdecke 2003).

International research collaboration has presented itself as both an asset and a constraint for the development of Antarctic research. By combining resources and technology from multiple actors, collaborative research has made it easier to deal with problems in scientific research, which are difficult for individuals or single organizations to solve. Joint investment and technical collaboration can lower the risk of investment and increase scientific capacity.

The IPY was launched in the 19th century to secure consistency in observing a wide range of natural phenomena with global impacts (Summerhayes 2008). It led to the emergence of intergovernmental programmes and structures that set the agenda for Antarctic research such as the International Geophysical Year of 1957-58 and the IPY of 2007-09 (Summerhayes 2008). The Antarctic Treaty System, through which the region is governed (Hanessian 1960), and SCAR were the major outcomes of the International Geophysical Year. The Antarctic Treaty has encouraged international cooperation by demilitarizing the Antarctic continent after the Cold War and by offering a platform to discuss common issues affecting humanity (Chown et al. 2012; Bray 2016; Petrică 2017). Diverse issues, such as the rights to biological resources, the environmental impact of research activities in Antarctica and the management and sharing of data, are discussed in an international context (Summerhayes 2008). SCAR has played a critical coordinating role in scientific research on Antarctica since the committee's founding in 1958. SCAR sets the agenda by leading working groups for the development of Antarctic research (SCAR 2010). It has also functioned as a nongovernmental international organization operating under the regime of the Antarctic Treaty (Elzinga 2009; Jang et al. 2016). Other organizations are part of this system and are represented in the Antarctic Treaty Consultative Meetings, such as the Antarctic and Southern Ocean Coalition, and the International Association of Antarctica Tour Operators. As these organizations and committees become more organized, they have provided researchers with various incentives, such as providing funding, education and collaboration opportunities, and have also guided individual researchers to produce consistent and shareable results.

Several studies have examined the collaborative features of Antarctic research by looking at published outputs. Aksnes \& Hessen (2009) suggested that the main feature of polar research is the increasing tendency towards greater international collaboration. They found that international collaborative research made up $10 \%$ of total publications in the early 1980s, rising to $41 \%$ by 2007. Countries that had published more articles were found to be more active in pursuing international collaborative research (international co-authorship) in later years. Dastidar \& Ramachandran (2008) reported that 
countries with higher productivity (a larger number of published articles) were more active in collaborative activities. Erb (2011) also found that collaborative journal publications are more frequent in Antarctic research than elsewhere.

These studies had some limitations in describing the collaborative structure in Antarctic research, however. Aksnes \& Hessen (2009) combined Arctic and Antarctic research, even though the two regions have different natural and political environments. Dastidar \& Ramachandran (2008) and Jang et al. (2016) added important pieces of evidence that shows the growing body of the literature and international collaborations in Antarctic research by drawing on SNA approaches. However, Dastidar \& Ramachandran (2008) covered the data only up to 2004, after which time the structure of Antarctic research has changed considerably. Their study was also limited to articles that included "Antarc*" in the title, which probably excluded some Antarctic-related journal articles. Jang et al. (2016) described the rapidly evolving landscape of growing international collaborations in Antarctic research by using more comprehensive data coverage based on keywords related to Antarctica (Jang et al. 2016). However, the focus of their study was South Korea.

To help fill out our understanding of international scientific collaboration in Antarctic research, this study builds on previous research and other literature and performs SNA of co-author relationships, thereby supplementing the limited findings of previous research.

\section{Academic research network}

There have been broad applications of SNA to research collaboration studies in the social and natural sciences (Newman 2001; Barabási et al. 2002; Grossman \& Erdo 2002). Two general approaches are found in the literature. The first approach focuses on the structural properties of the network itself and its changes in a macroscopic perspective. This perspective examines the entire structure and evolution of the network by using structural measures, such as density and clustering coefficients (Newman 2001; Barabási et al. 2002; Otte \& Rousseau 2002; Watts \& Strogatz 2011; Borrett et al. 2014). The second approach takes a more microscopic view by focusing on identifying and interpreting specific nodes and ties (Wellman 1983; Wasserman \& Faust 1994). Many studies have tried to find key actors or meaningful subgroups within the network structure of collaboration (Leydesdorff 2007; Boardman 2009; Abbasi et al. 2012). This approach is beneficial, especially for identifying the central individual or organizational actor within the collaborative structure.
Many network structure studies use a variety of methods and indices (e.g., degree centrality and clustering coefficients) to compare and analyse the individual properties of nodes in each network. These SNA methods are based on the premise that high-status nodes in the network are likely to have a significant influence on other individuals connected directly and indirectly to them.

This study seeks to apply both macro- and microscopic SNA approaches to understand the collaborative structure of Antarctic research. From the macroscopic perspective, we attempt to analyse patterns, in which academic fields are represented in the relevant journal articles through the years. From the microscopic perspective, we attempt to identify the countries playing key roles in Antarctic research publications.

\section{Data and methods}

\section{Data}

In this study, we extracted bibliographic data on Antarctic-related articles from the WoS database by developing a search query that includes keywords related to Antarctica. Using a simple search word, such as "Antarctic*," or looking at only selected journals, might be an intuitive way of identifying Antarctic journal articles; however, such methods may omit a significant number of studies. For example, one of the most cited articles in our data set, entitled "A mesoscale phytoplankton bloom in the polar Southern Ocean stimulated by iron fertilization" (Boyd et al. 2000), cannot be captured by "Antarctic*" because it does not include the term in the title, keywords or abstract.

To overcome this challenge, we used two-step extractions in making the data set. In the first stage, we downloaded the initial set of references with a simple keyword, "Antarctic*" and extracted a set of 864 keywords directly related to Antarctica from titles, keywords and abstracts (see Supplementary material). These keywords were primarily place names (such as "Byers Peninsula"), research station names (such as Concordia Station) and species names (such as "Cryptopygus antarticus" and "elephant seal"). We then used these keywords to identify 78916 relevant articles published between 1998 and 2015.

In the second stage, we obtained the data-such as the national affiliations of each co-author-from these articles. The body of articles was reduced to 78445 after 471 articles that omitted institutional or country information were excluded from the data set.

We later reclassified the data by using the OECD Category Scheme (NESTI Working Party 2007) to compare 
the subfields of Antarctic research. The OECD scheme classifies science and technology fields using six major codes (natural sciences, engineering and technology, medical and health sciences, agricultural sciences, social sciences and humanities) and 42 minor codes (NESTI Working Party 2007).

WoS classifies articles based on the journals, in which they are published; many of the journals belong to multiple categories. When an article had been published in a journal belonging to more than one WoW category, for the purpose of our analysis, we classified it as either belonging to multidisciplinary sciences or to one of the six major OECD fields. If all the categories to which a journal belonged fell into one of the major categories, then the article was classified as belonging to that major category. For example, Journal of Insect Physiology is included in three categories in WoS-entomology, physiology and zoology-which are all subfields of natural sciences, so for the purpose of this study, Antarctic-related articles in this journal were classified as natural sciences articles. If a journal belonged to categories that did not fall under a single major category, articles in that journal were categorized as representing multidisciplinary sciences. For example, Environmental Science $\theta$ Technology has two categories in WoS: engineering (major OECD category: engineering and technology) and environmental sciences $\delta$ ecology (major OECD category: natural sciences). Articles in this journal were classified as multidisciplinary sciences.

\section{Methods}

With a focus on international collaborative research, we analysed the form of the collaborative networks built by individual countries for research by year by drawing on descriptive statistics and four centrality measures commonly used in SNA studies that assess the network property of each country: degree centrality, closeness centrality, betweenness centrality and eigenvector centrality.

First, degree centrality indicates how many direct ties an actor has with alters in the network. In the context of international collaboration, a country with more ties may be more likely to influence the field by having more connections with other countries. Equation 1 shows how to calculate degree centrality (Freeman 1978).

$$
C_{D}\left(N_{i}\right)=\sum_{j=1}^{g} x_{i j}, i \neq j
$$

$C_{D}\left(N_{i}\right)$ denotes the degree centrality of country $i, g$ is the number of countries, $\sum_{j=1}^{g} x_{i j}$ is the number of links that country $i$ has with other $(g-1)$ countries and $x_{i j}=$ 0 or 1 .
Second, closeness centrality considers both direct and indirect links in a network in estimating centrality. It emphasizes the distance between one actor and another within the whole network and is calculated as the function of the distance of the shortest paths between actors. Equation 2 expresses how closeness centrality is calculated.

$$
C_{C}\left(N_{i}\right)=\frac{1}{\sum_{j=1}^{g} d\left(N_{i}, N_{j}\right)}, i \neq j
$$

$C_{C}\left(N_{i}\right)$ denotes the closeness centrality of country $i$ and $\sum_{j=1}^{g} d\left(N_{\mathrm{i}}, N_{\mathrm{j}}\right)$ is the sum of the distances of the shortest paths between actor $i$ and actor $j$.

Third, betweenness centrality means the degree to which the links which are not directly connected within the network can be bridged. In the network, some actors might play a critical role by bridging relationships among other actors. Therefore, bridging countries can function as coordinators for information and resource exchanges that occur within the polar research network. They may increase the possibility of convergence research among different academic fields. Equation 3 expresses the method for measuring betweenness centrality.

$$
C_{B}\left(N_{i}\right)=\frac{g_{j k}\left(N_{i}\right)}{g_{j k}}, i \neq j
$$

$C_{B}\left(N_{i}\right)$ denotes the betweeness centrality of country $i$ and $g_{j k}$ denotes the number of short paths between actors $j$ and $k$.

Fourth, eigenvector centrality is an index that considers not only the number of actors connected but also their importance (Wasserman \& Faust 1994). In other words, the eigenvalue centrality of a node increases when it is connected to other highly connected nodes. Eigenvector centrality is calculated by the formula:

$$
C_{E}\left(N_{i}\right)=\lambda \sum_{j=1}^{g} x_{i j} C_{D}\left(N_{j}\right), i \neq j,
$$

where $C_{E}\left(N_{i}\right)$ denotes the eigenvalue centrality of country $i, g$ denotes the number of countries in the network and $x_{i j}$ is a binary indicator of the number of links between countries $i$ and $j$.

\section{Results and discussion}

\section{Output over time}

In our data set, the number of publications steadily increased during the period being examined. The natural sciences have the largest share among the six broad research areas and multidisciplinary sciences (Table 1). A 
Table 1 Number of articles by research area and year. The categories are drawn from the OECD science and technology classification (NESTI Working Party 2007).

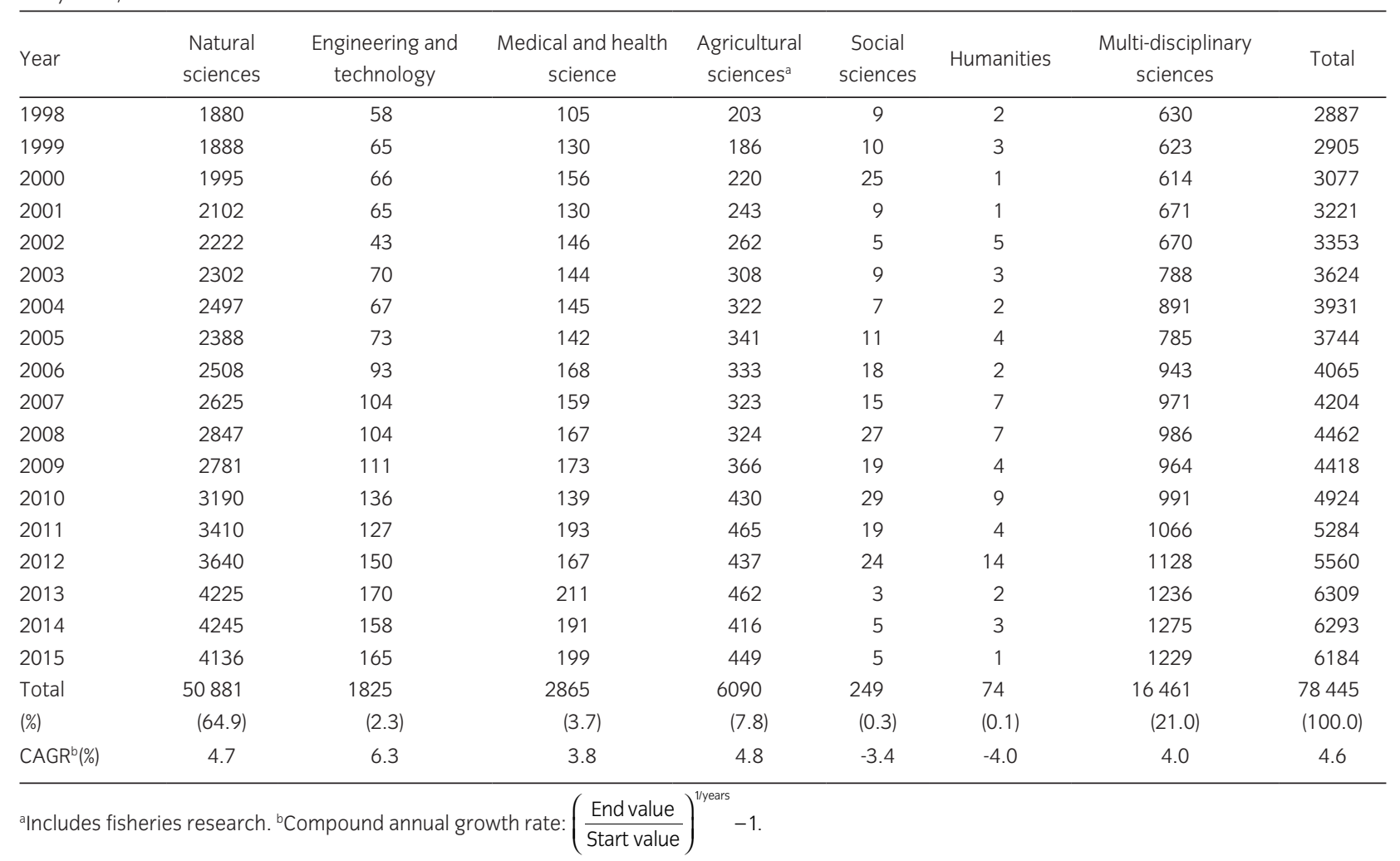

total of 50881 research articles-approximately $64.9 \%$ of the articles fell within this category.

\section{Articles with one author versus multiple authors}

Out of 78445 articles, 5220 articles (6.7\%) were single-authored, while the rest of the articles involved two or more authors (Table 2). This proportion of singleauthored articles is relatively low. Waltman $\delta$ van Eck (2015) reported that the proportion of single-authored articles (including review papers) published between 2009 and 2010 and in WoS was higher than 10\% in all fields.

In the category of natural sciences, the proportion of single-authored articles was 7.6\% (3876 articles), and the largest portion-15 623 articles $(29.3 \%)$-was written by two authors. The second-largest area-agricultural sciences-which included 6090 articles largely in the field of fisheries included $5.1 \%$ of single-authored articles. Multidisciplinary sciences had the lowest proportion of single-authored articles: $3.9 \%$. In contrast, the proportion of single-authored articles was considerably higher in the social sciences $(43.4 \%)$ and humanities $(81.1 \%)$. This may reflect the general solo-authorship tendency in these fields, though co-authorship has become increasingly typical in the fields as well (Henriksen 2015; Macfarlane et al. 2017).

\section{International co-authorship}

The proportion of international collaborations that involved two or more countries continuously increased from 1998 to 2015 (Table 3). We defined an international collaboration in this study as an article written by two or more authors affiliated with organizations located in different countries. Ninety-one articles written by a single author who was affiliated with multiple organizations located in different countries were coded as single-country articles. With the steady increase in the proportion of multi-authored articles, the proportion of multi-countries articles increased from $23.3 \%$ in 1998 to $39.8 \%$ in 2015 (Fig. 1).

As of 2015, the natural sciences had the highest percentage of multi-countries articles, $38.5 \%$, followed by $27.9 \%$ of the fields of medical and health science and $25.9 \%$ of multidisciplinary sciences (Table 4 ).

Although there were variations across the fields, the overall trend was that the percentage of multi-countries articles increased from $23.0 \%$ in 1998 to $39.8 \%$ in 2015 (Fig. 2). 
Table 2 Number of authors by research field. The categories drawn from the OECD science and technology classification (NESTI Working Party 2007).

\begin{tabular}{|c|c|c|c|c|c|c|c|c|}
\hline $\begin{array}{l}\text { Number of } \\
\text { authors }\end{array}$ & $\begin{array}{c}\text { No. of } \\
\text { natural sciences } \\
\text { articles (\%) }\end{array}$ & $\begin{array}{c}\text { No. of } \\
\text { engineering } \\
\text { and technology } \\
\text { articles (\%) }\end{array}$ & $\begin{array}{c}\text { No. of } \\
\text { medical and } \\
\text { health science } \\
\text { articles (\%) }\end{array}$ & $\begin{array}{c}\text { No. of } \\
\text { agricultural } \\
\text { sciences }^{\text {a }} \text { articles } \\
(\%)\end{array}$ & $\begin{array}{c}\text { No. of } \\
\text { social } \\
\text { sciences } \\
\text { articles (\%) }\end{array}$ & $\begin{array}{c}\text { No. of } \\
\text { humanities } \\
\text { articles (\%) }\end{array}$ & $\begin{array}{c}\text { No. of } \\
\text { multi-disciplinary } \\
\text { sciences } \\
\text { articles (\%) }\end{array}$ & Total (\%) \\
\hline 1 & $3876(7.6)$ & $101(5.5)$ & $117(4.1)$ & $308(5.1)$ & $108(43.4)$ & $60(81.1)$ & $650(3.9)$ & $5220(6.7)$ \\
\hline 2 & $9418(18.5)$ & $271(14.8)$ & $400(14.0)$ & $1108(18.2)$ & 48 (19.3) & $8(10.8)$ & 2507 (15.2) & 13760 (17.5) \\
\hline 3 & 10125 (19.9) & $348(19.1)$ & $528(18.4)$ & 1307 (21.5) & 32 (12.9) & $3(4.1)$ & 3266 (19.8) & 15609 (19.9) \\
\hline 4 & 8775 (17.2) & $384(21.0)$ & $524(18.3)$ & 1185 (19.5) & $25(10.0)$ & $2(2.7)$ & 3115 (18.9) & 14010 (17.9) \\
\hline 5 & $6612(13.0)$ & $300(16.4)$ & $435(15.2)$ & $863(14.2)$ & $17(6.8)$ & $1(1.4)$ & $2538(15.4)$ & $10766(13.7)$ \\
\hline 6 & $4225(8.3)$ & $175(9.6)$ & $302(10.5)$ & $569(9.3)$ & $12(4.8)$ & & $1768(10.7)$ & 7051 (9.0) \\
\hline 7 & $2748(5.4)$ & $111(6.1)$ & $244(8.5)$ & $340(5.6)$ & $4(1.6)$ & & $1115(6.8)$ & $4562(5.8)$ \\
\hline 8 & $1715(3.4)$ & $66(3.6)$ & 125 (3.2) & $196(3.2)$ & $1(0.4)$ & & $624(3.8)$ & 2727 (3.5) \\
\hline 9 & 991 (1.9) & $23(1.3)$ & $70(1.6)$ & $96(1.6)$ & & & $345(2.2)$ & 1534 (2.0) \\
\hline 10 or more & $2396(4.7)$ & $46(2.5)$ & $120(1.9)$ & 118 (1.9) & $2(0.8)$ & & $524(3.2)$ & $3206(4.1)$ \\
\hline Total & $50881(100.0)$ & $1825(100.0)$ & 2865 (100.0) & $6090(100.0)$ & 249 (100.0) & $74(100.0)$ & $16460(100.0)$ & 78445 (100.0) \\
\hline
\end{tabular}

ancludes fisheries research.

Table 3 Proportions of single-authored, multi-authored, single-country and multi-countries articles by year.

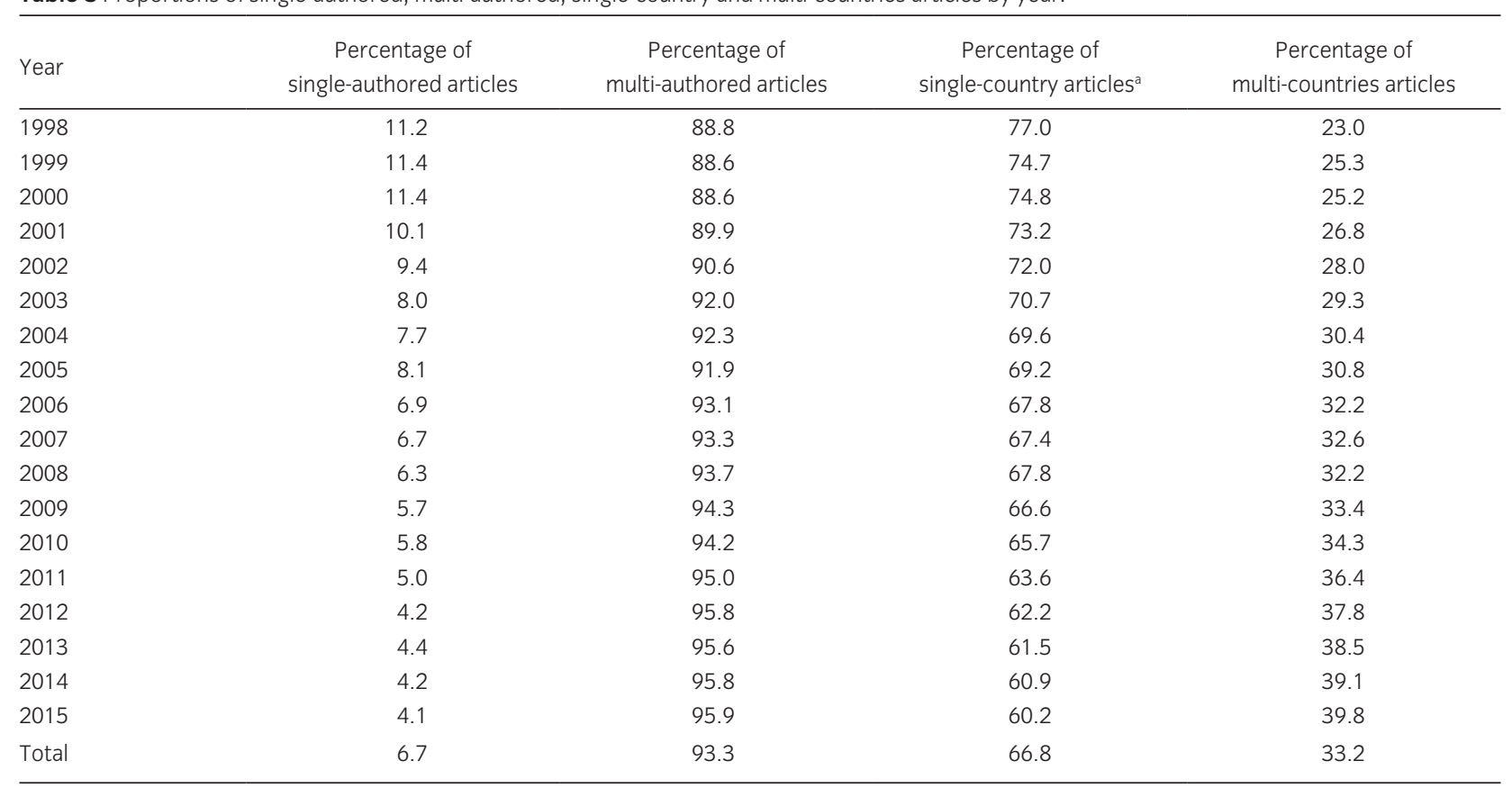

asingle-country articles include articles written by one author or a group of authors affiliated with more than one organization located in one country.

\section{Output by country}

The United States published the largest number of articles (Table 5). From 1998 to 2015, 18445 articles were first-authored by those from institutions located in the United States. The United Kingdom and Canada were ranked second and third, with 6031 and 5752 articles, respectively.

There was a gradual increase in the number of countries that in the upper 80th percentile in terms of article authorship (Table 5). In 1998, 11 countries produced 80\% of the articles in the field, but by 2015, this number had increased to 17 countries. Compared with the increase in the number of articles published by the countries in the 80th percentile of the articles, there was an even greater increase in the number of articles presented by newly emerging countries (Supplementary Table S1). Towards the end of the period being examined, decreases in the shares of the countries that had initially led the field are also noteworthy. 


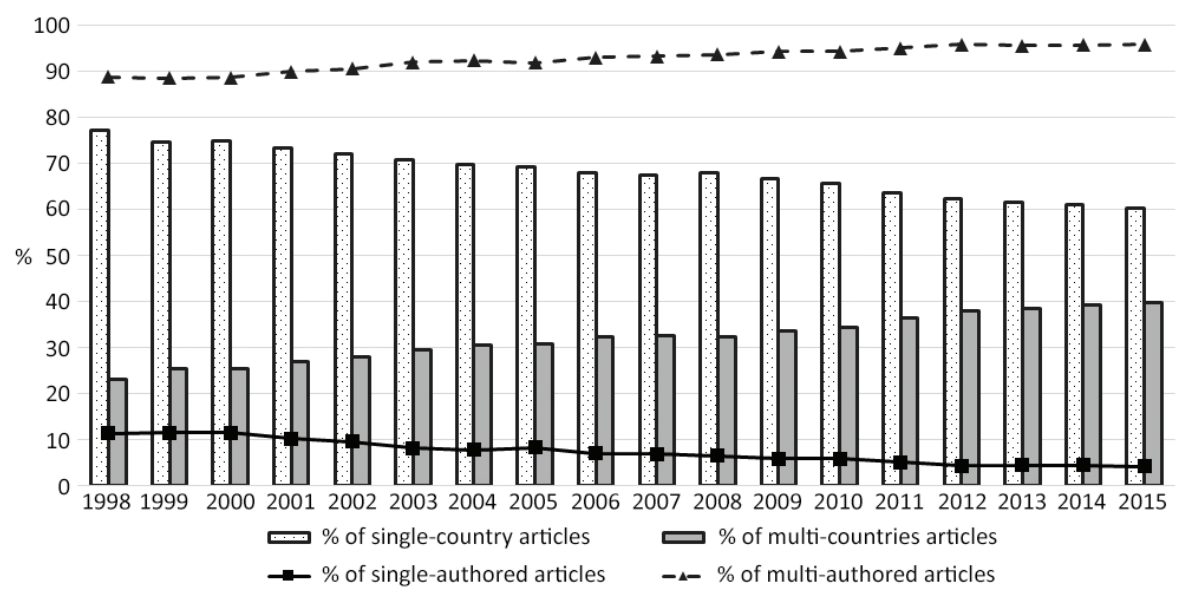

Fig. 1 Trends of single-authored, multi-authored, single-country and multi-countries articles.

Table 4 Percentage of multi-countries articles by research field. The categories are drawn from the OECD science and technology classification (NESTI Working Party 2007).

\begin{tabular}{|c|c|c|c|c|c|c|c|}
\hline Research field & 1998 & 2000 & 2005 & 2010 & 2015 & Total & $\begin{array}{c}\text { Total number } \\
\text { of articles }\end{array}$ \\
\hline Natural sciences & 26.3 & 27.4 & 34.8 & 40.8 & 46.0 & 38.5 & 50881 \\
\hline Engineering and technology & 6.9 & 12.1 & 19.2 & 16.2 & 26.1 & 18.8 & 1825 \\
\hline Medical and health sciences & 13.3 & 28.2 & 30.3 & 31.7 & 34.7 & 27.9 & 2865 \\
\hline Agricultural sciences ${ }^{a}$ & 10.3 & 13.6 & 15.0 & 15.1 & 19.6 & 16.1 & 6090 \\
\hline Humanities & 0.0 & 0.0 & 0.0 & 0.0 & 0.0 & 5.4 & 74 \\
\hline Multidisciplinary sciences & 20.5 & 23.5 & 26.9 & 25.4 & 29.0 & 25.9 & 16461 \\
\hline
\end{tabular}

ancludes fisheries research.

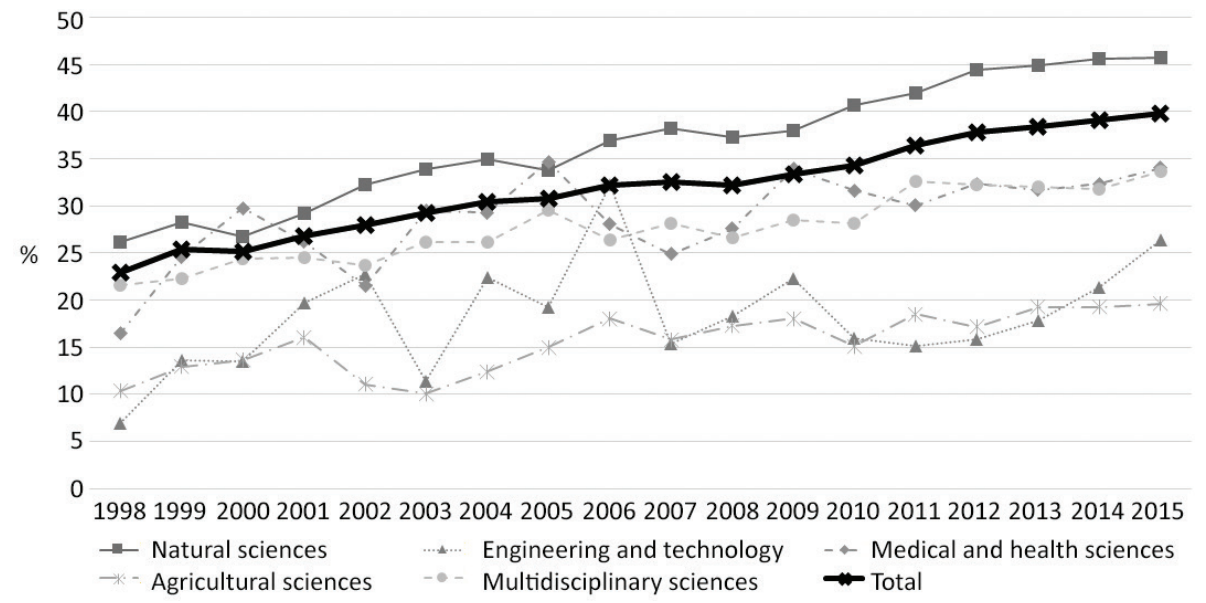

Fig. 2 Yearly trend in the percentage of multi-countries articles by research field. The fields of the social sciences and humanities are excluded because of their inconsistent trends due to the small numbers of observations. 


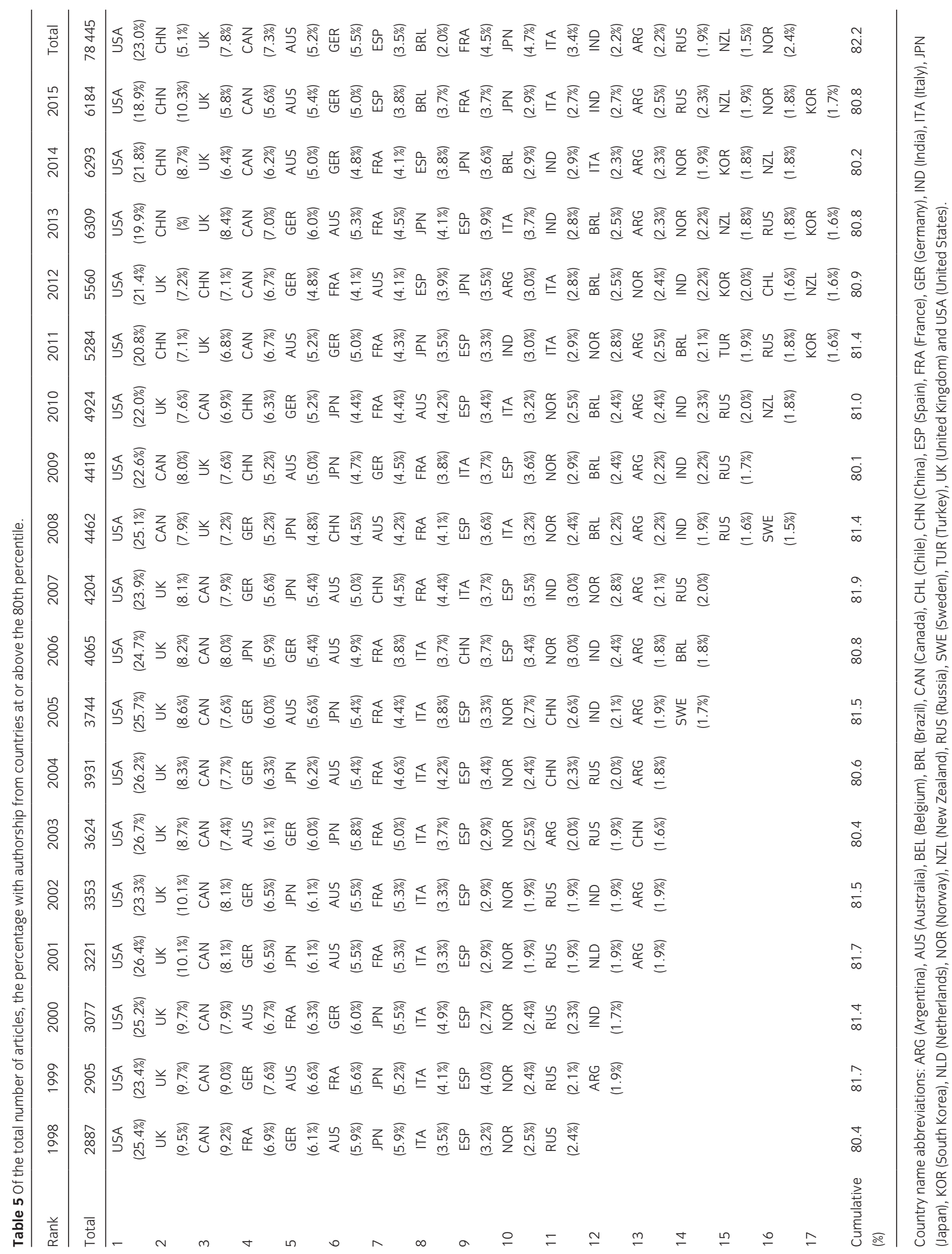




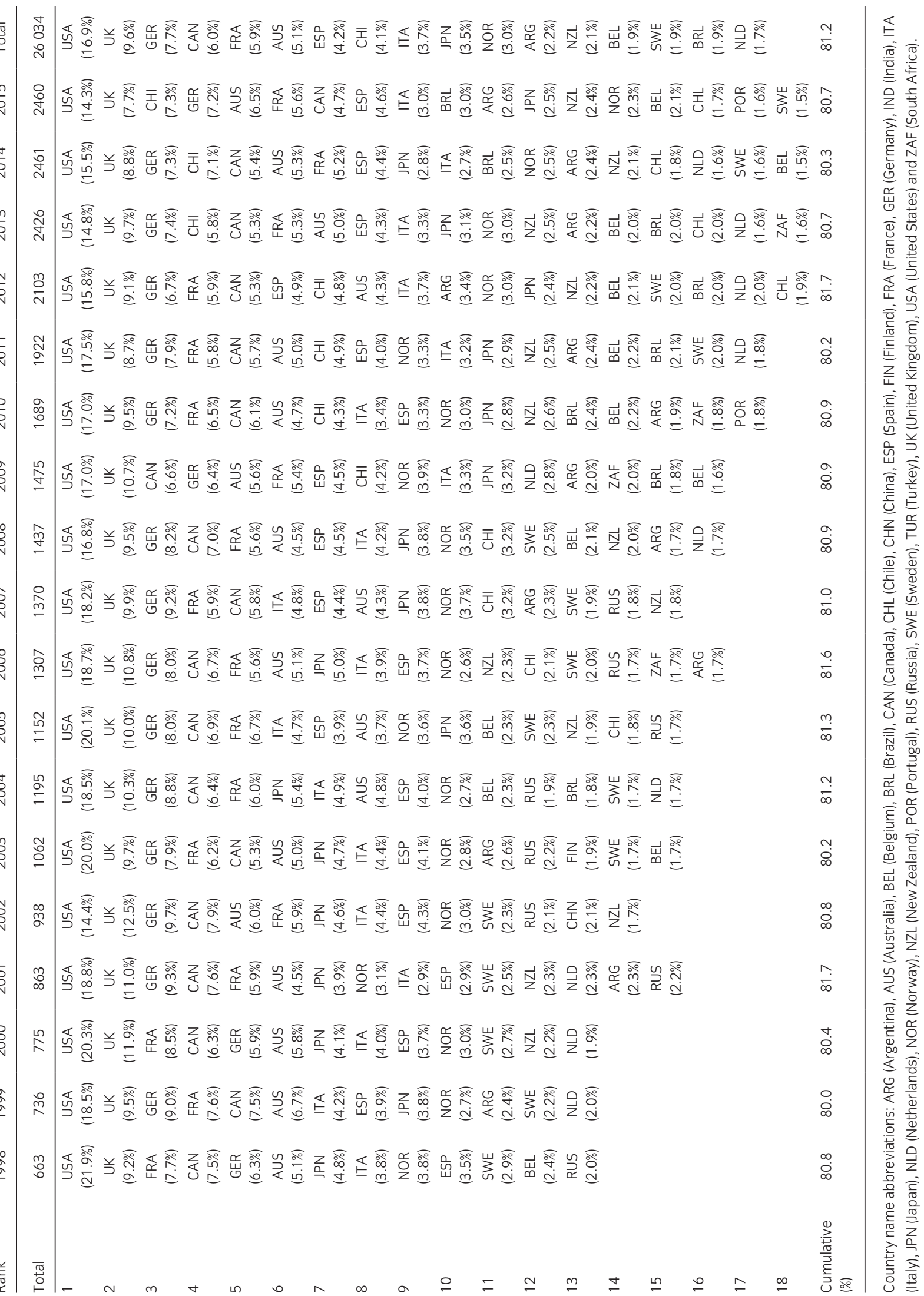


Table 7 Network analysis results: multi-countries articles in all research fields. Degree centrality indicates how many direct ties the node has. Closeness centrality indicates how close the node is with the other nodes. Betweenness centrality indicates how the node bridges relations between the other nodes. Eigenvector centrality indicates how the node is connected to highly connected nodes.

\begin{tabular}{|c|c|c|c|c|}
\hline Rank & Degree centrality & Closeness centrality & Betweenness centrality & Eigenvector centrality \\
\hline$\overline{1}$ & USA (0.833) & USA $(0.857)$ & USA (0.173) & USA (0.599) \\
\hline 2 & UK $(0.707)$ & UK (0.773) & FRA (0.080) & GER (0.380) \\
\hline 3 & $\operatorname{GER}(0.701)$ & GER $(0.770)$ & GER (0.076) & UK $(0.367)$ \\
\hline 4 & FRA (0.684) & FRA $(0.760)$ & AUS (0.071) & FRA (0.315) \\
\hline 5 & AUS (0.644) & AUS (0.737) & UK (0.067) & ITA (0.254) \\
\hline 7 & ITA (0.529) & ITA $(0.680)$ & CAN $(0.034)$ & SPA (0.159) \\
\hline 8 & CHN (0.529) & CHN (0.680) & NZL (0.032) & AUS (0.150) \\
\hline 9 & ZAF (0.506) & ZAF (0.669) & CHN (0.030) & JPN (0.112) \\
\hline 10 & JPN (0.506) & JPN (0.669) & ARG (0.029) & BEL (0.108) \\
\hline 11 & BEL (0.506) & BEL (0.669) & ZAF (0.029) & SWE $(0.100)$ \\
\hline 12 & SWE (0.489) & SWE (0.662) & NLD (0.027) & CHE (0.090) \\
\hline 14 & NOR $(0.471)$ & NOR (0.654) & ITA (0.020) & CHL (0.074) \\
\hline 15 & NLD (0.471) & NLD (0.654) & SPA (0.016) & NOR (0.073) \\
\hline 16 & CHE (0.460) & CHE (0.649) & $\operatorname{MEX}(0.015)$ & NZL (0.072) \\
\hline 17 & BRL (0.443) & BRL $(0.642)$ & SWE (0.014) & $\mathrm{CHN}(0.071)$ \\
\hline 18 & DEN $(0.431)$ & DEN (0.637) & RUS (0.013) & RUS (0.070) \\
\hline 19 & RUS (0.425) & RUS (0.635) & DEN (0.012) & DEN (0.062) \\
\hline 20 & NZL (0.425) & NZL (0.635) & CHE (0.012) & FIN (0.060) \\
\hline 21 & POL (0.402) & POL (0.626) & $\operatorname{NOR}(0.011)$ & ZAF (0.048) \\
\hline 22 & IND (0.397) & IND (0.624) & IND (0.008) & ARG (0.036) \\
\hline 23 & POR (0.391) & POR (0.621) & BRL (0.008) & BRL (0.029) \\
\hline 24 & CHL (0.391) & ARG (0.621) & AUT (0.008) & KOR (0.028) \\
\hline 25 & ARG (0.391) & $\mathrm{CHL}(0.619)$ & POR (0.007) & TWN (0.027) \\
\hline 26 & AUT (0.385) & AUT (0.619) & POL (0.007) & POL (0.026) \\
\hline 27 & KOR (0.362) & KOR (0.611) & $\mathrm{CHL}(0.007)$ & POR (0.023) \\
\hline 29 & TUR (0.322) & TUR (0.596) & SRB $(0.006)$ & $\operatorname{MEX}(0.014)$ \\
\hline 30 & THA (0.322) & THA (0.594) & SVN (0.006) & AUT (0.013) \\
\hline
\end{tabular}

Country name abbreviations: ARG (Argentina), AUS (Australia), AUT (Austria), BEL (Belgium), BRL (Brazil), CAN (Canada), CHE (Switzerland), CHL (Chile), CHN (China), CZE (Czech Republic), DEN (Denmark), ESP (Spain), FIN (Finland), FRA (France), GER (Germany), IND (India), ITA (Italy), JPN (Japan), KOR (South Korea), MEX (Mexico), NLD (Netherlands), NOR (Norway), NZL (New Zealand), POL (Poland), POR (Portugal), RUS (Russia), SRB (Serbia), SVN (Slovenia), SWE (Sweden), THA (Thailand), TUR (Turkey), TWN (Taiwan), UK (United Kingdom), USA (United States) and ZAF (South Africa).

Some other countries entered the 80th percentile by increasing their shares in the number of publications. China and Brazil, in particular, showed a large increase in the percentage of the number of publications. In the period analysed, China showed the most substantial increase. China first entered the top 80th percentile in 2003, with a share of $1.6 \%$. However, as of 2015 , China took $10.3 \%$ of the share, by following the United States. Similar to China, Brazil remained below the $80 \%$ range until 2005 but entered the top $80 \%$ for the first time in 2008. As of 2015, Brazil took 3.7\% of the publications and was ranked as eighth in the number of publications.

Table 6 modifies Table 5 by limiting the data to multi-countries articles. It demonstrates that countries that published a relatively large number of articles, such as the United States, the United Kingdom, Germany and France, also tended to take a large share in the number of multi-countries articles. Second, some countries not visible in Table 5 show a larger share in Table 6, indicating their important roles in international collaboration. Leading examples here include Sweden, Belgium and the Netherlands, which are not in the upper 80th percentile in Table 5 but take about $1-2 \%$ in international collaborative research (Table 6).

Of all the research articles on Antarctica published from 1998 to 2015, the number of articles produced by the United States grew each year except for 2015, whereas the percentage gradually decreased. The decrease in percentage was almost entirely due to an increase in productivity by authors from other countries, such as China, 


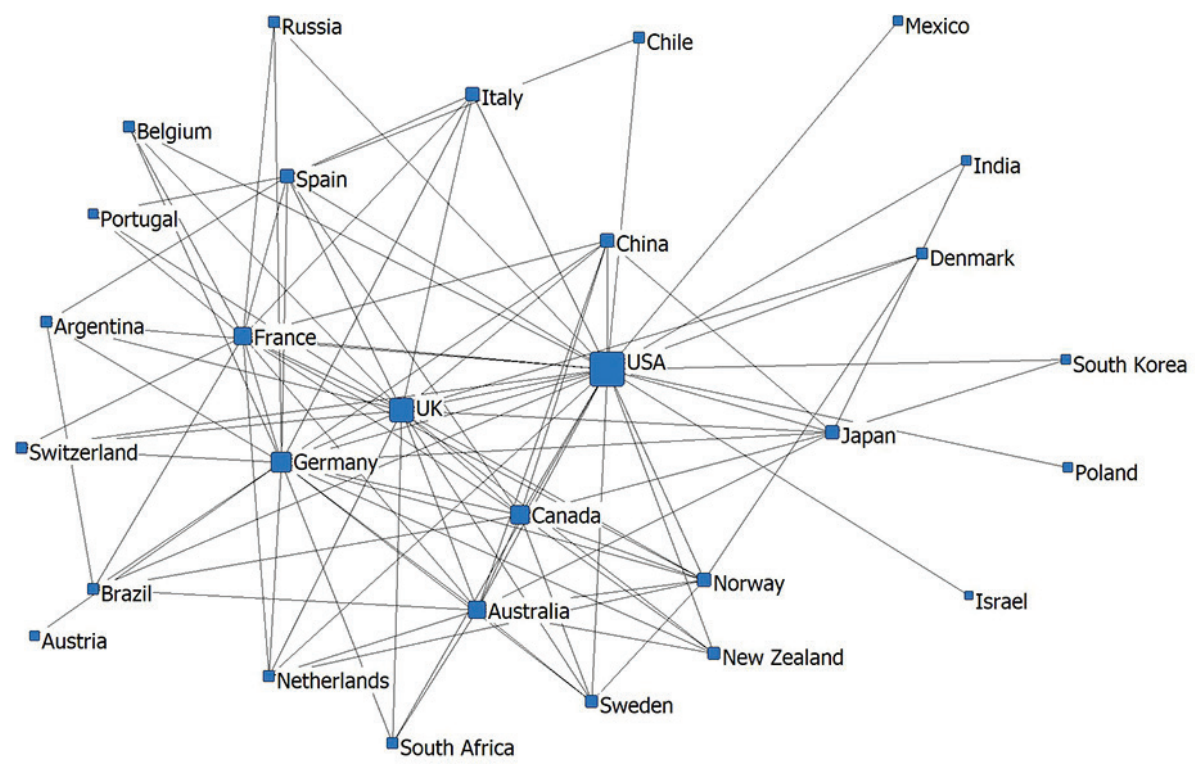

Fig. 3 Network of international collaborative articles in all research fields focusing on degree centrality. This figure visualizes trends in international collaborative research among countries. The links are limited to those with a frequency of 100 or higher. Node sizes represent the number of links connected to each node.

Table 8 Number of articles by subfield within the natural sciences, by year. The categories are drawn from the OECD science and technology classification (NESTI Working Party 2007).

\begin{tabular}{|c|c|c|c|c|c|c|}
\hline Year & Mathematics & $\begin{array}{c}\text { Computer and } \\
\text { information sciences }\end{array}$ & $\begin{array}{l}\text { Physical sciences } \\
\text { and astronomy }\end{array}$ & $\begin{array}{l}\text { Chemical } \\
\text { sciences }\end{array}$ & $\begin{array}{c}\text { Earth and related } \\
\text { environmental sciences }\end{array}$ & $\begin{array}{l}\text { Biological } \\
\text { sciences }\end{array}$ \\
\hline 1998 & 7 & 3 & 117 & 124 & 1184 & 1286 \\
\hline 1999 & 4 & 6 & 133 & 124 & 1160 & 1264 \\
\hline 2000 & 4 & 3 & 104 & 111 & 1255 & 1277 \\
\hline 2001 & 5 & 4 & 127 & 127 & 1302 & 1404 \\
\hline 2002 & 5 & 5 & 124 & 121 & 1478 & 1374 \\
\hline 2003 & 10 & 2 & 144 & 155 & 1491 & 1418 \\
\hline 2004 & 3 & 3 & 182 & 177 & 1652 & 1556 \\
\hline 2005 & 5 & 2 & 168 & 171 & 1567 & 1500 \\
\hline 2006 & 6 & 10 & 144 & 187 & 1646 & 1632 \\
\hline 2007 & 8 & 2 & 118 & 191 & 1697 & 1699 \\
\hline 2008 & 5 & 7 & 140 & 203 & 1913 & 1794 \\
\hline 2009 & 12 & 6 & 158 & 191 & 1769 & 1855 \\
\hline 2010 & 11 & 6 & 167 & 222 & 2057 & 2041 \\
\hline 2011 & 7 & 10 & 174 & 216 & 2275 & 2021 \\
\hline 2012 & 6 & 8 & 261 & 211 & 2314 & 2156 \\
\hline 2013 & 11 & 6 & 277 & 270 & 2712 & 2377 \\
\hline 2014 & 12 & 11 & 221 & 243 & 2795 & 2464 \\
\hline 2015 & 12 & 12 & 228 & 304 & 2603 & 2443 \\
\hline Total & 133 & 106 & 2987 & 3348 & 32870 & 31561 \\
\hline
\end{tabular}


Table 9 Multi-countries collaborative research in Earth and related environmental sciences and the biological sciences.

\begin{tabular}{|c|c|c|c|c|c|c|}
\hline \multirow[b]{2}{*}{ Year } & \multicolumn{3}{|c|}{ Earth and related environmental sciences } & \multicolumn{3}{|c|}{ Biological sciences } \\
\hline & $\begin{array}{c}\text { No. of } \\
\text { single-country } \\
\text { articles }\end{array}$ & $\begin{array}{c}\text { No. of } \\
\text { multi-countries } \\
\text { articles }\end{array}$ & $\begin{array}{c}\% \text { of } \\
\text { multi-countries } \\
\text { articles }\end{array}$ & $\begin{array}{c}\text { No. of } \\
\text { single-country } \\
\text { articles }\end{array}$ & $\begin{array}{c}\text { No. of } \\
\text { multi-countries } \\
\text { articles }\end{array}$ & $\begin{array}{c}\% \text { of } \\
\text { multi-countries } \\
\text { articles }\end{array}$ \\
\hline 1998 & 856 & 328 & 27.7 & 980 & 306 & 23.8 \\
\hline 1999 & 817 & 343 & 29.6 & 921 & 343 & 27.1 \\
\hline 2000 & 901 & 354 & 28.2 & 945 & 332 & 26.0 \\
\hline 2001 & 918 & 384 & 29.5 & 1055 & 349 & 24.9 \\
\hline 2002 & 982 & 496 & 33.6 & 987 & 387 & 28.2 \\
\hline 2003 & 985 & 506 & 33.9 & 988 & 430 & 30.3 \\
\hline 2004 & 1041 & 611 & 37.0 & 1060 & 496 & 31.9 \\
\hline 2005 & 1019 & 548 & 35.0 & 1032 & 468 & 31.2 \\
\hline 2006 & 1001 & 645 & 39.2 & 1087 & 545 & 33.4 \\
\hline 2008 & 1183 & 730 & 38.2 & 1200 & 594 & 33.1 \\
\hline 2009 & 1074 & 695 & 39.3 & 1198 & 657 & 35.4 \\
\hline 2010 & 1189 & 868 & 42.2 & 1311 & 730 & 35.8 \\
\hline 2011 & 1268 & 1007 & 44.3 & 1268 & 753 & 37.3 \\
\hline 2012 & 1284 & 1030 & 44.5 & 1314 & 842 & 39.1 \\
\hline 2013 & 1466 & 1246 & 45.9 & 1455 & 922 & 38.8 \\
\hline 2014 & 1482 & 1313 & 47.0 & 1480 & 984 & 39.9 \\
\hline 2015 & 1354 & 1249 & 48.0 & 1403 & 1040 & 42.6 \\
\hline Total & 19853 & 13017 & 39.6 & 20781 & 10780 & 34.2 \\
\hline
\end{tabular}

Turkey, Brazil, South Korea and Chile. For example, as of 2015, China ranked second in the world in terms of the number of articles on Antarctica (Table 5), outstripping the United Kingdom and Canada, which ranked as the third and fourth, respectively.

\section{SNA results: a network of multinational collaborative research in all research fields}

This section describes SNA results by focusing on 26034 articles co-authored by authors from at least two different countries (Table 7).

The United States had the highest values for all centrality measures (Table 7), implying that the United States was engaged in international collaborative research in Antarctic research with the largest number of countries. Other countries in the upper ranks include the United Kingdom, France, Germany, Australia, Italy, Canada, Belgium, China, New Zealand and South Africa. Many of these countries have a scientific research station located in Antarctica and, with a few exceptions, most are considered to be advanced in research and development.

The United States engaged in collaborative research with most of the countries in the network (Fig. 3). Some countries did not have 100 or more links with countries other than the United States. Leading examples in this group are South Africa, Austria, Israel, Mexico and Poland, which did not frequently collaborate on articles with countries other than the United States.

Some European countries, such as Germany, the United Kingdom, France and Italy, along with Australia, constituted a third group that collaborated not only with the United States but also with other countries in Europe. One possible reason why these and other European countries collaborated to the large extent that they did is related to joint European Union funding, but more in-depth research is required to confirm this or to identify other reasons for the high degree of collaborative publications (and research) among smaller European countries.

\section{SNA results: network of multinational collaborative research in the natural sciences}

In this section, we dive into two subfields in the natural sciences category: Earth and related environmental sciences and biological sciences. The greatest percentage of articles in our data set comes from the natural sciences, among the seven major fields of scholarship. The natural sciences can be divided into the following subfields, as classified by the OECD (NESTI Working Party 2007): mathematics and computer sciences; physical sciences; 
Table 10 SNA results: Earth and related environmental sciences and the biological sciences. Degree centrality indicates how many direct ties the node has. Closeness centrality indicates how close the node is with the other nodes. Betweenness centrality indicates how the node bridges relations between the other nodes. Eigenvector centrality indicates how the node is connected to highly connected nodes.

\begin{tabular}{|c|c|c|c|c|c|c|c|c|}
\hline \multirow[b]{2}{*}{ Rank } & \multicolumn{4}{|c|}{ Earth and related environmental sciences } & \multicolumn{4}{|c|}{ Biological sciences } \\
\hline & $\begin{array}{l}\text { Degree } \\
\text { centrality }\end{array}$ & $\begin{array}{l}\text { Closeness } \\
\text { centrality }\end{array}$ & $\begin{array}{c}\text { Betweenness } \\
\text { centrality }\end{array}$ & $\begin{array}{l}\text { Eigenvector } \\
\text { centrality }\end{array}$ & $\begin{array}{l}\text { Degree } \\
\text { centrality }\end{array}$ & $\begin{array}{l}\text { Closeness } \\
\text { centrality }\end{array}$ & $\begin{array}{c}\text { Betweenness } \\
\text { centrality }\end{array}$ & $\begin{array}{c}\text { Eigenvector } \\
\text { centrality }\end{array}$ \\
\hline 1 & USA (0.688) & USA (0.759) & USA (0.221) & USA (0.960) & USA (0.600) & USA (0.144) & USA (0.705) & USA (0.965) \\
\hline 2 & GER (0.576) & $\operatorname{GER}(0.700)$ & FRA (0.149) & UK (0.169) & UK $(0.600)$ & UK (0.135) & UK (0.701) & CAN (0.169) \\
\hline 3 & UK $(0.556)$ & FRA (0.689) & GER (0.107) & CAN (0.114) & GER (0.578) & GER $(0.128)$ & GER (0.694) & UK (0.119) \\
\hline 4 & FRA (0.556) & UK (0.689) & UK (0.105) & AUS (0.104) & FRA $(0.541)$ & FRA (0.116) & FRA $(0.676)$ & AUS (0.088) \\
\hline 5 & AUS (0.472) & AUS $(0.651)$ & AUS (0.077) & GER (0.088) & AUS (0.422) & BEL (0.062) & AUS (0.618) & GER (0.062) \\
\hline 6 & CAN (0.403) & CAN (0.623) & $J P N(0.041)$ & $\mathrm{CHN}(0.067)$ & CAN $(0.407)$ & AUS (0.043) & CAN (0.615) & FRA (0.051) \\
\hline 7 & JPN (0.375) & JPN (0.607) & NZL (0.036) & FRA $(0.065)$ & BEL $(0.407)$ & CAN (0.043) & BEL $(0.612)$ & JPN (0.046) \\
\hline 8 & $\operatorname{ESP}(0.347)$ & $\operatorname{ESP}(0.602)$ & ARG (0.034) & JPN (0.038) & SWE (0.378) & NZL (0.043) & ITA (0.603) & NZL (0.045) \\
\hline 9 & $\mathrm{CHN}(0.340)$ & CHN (0.597) & CHN (0.032) & NZL (0.037) & $\operatorname{ITA}(0.370)$ & POL (0.036) & SWE (0.603) & ITA (0.037) \\
\hline 10 & BEL (0.333) & BEL (0.597) & CAN (0.031) & ITA $(0.037)$ & $\operatorname{ESP}(0.370)$ & NET (0.032) & $\operatorname{ESP}(0.598)$ & $\mathrm{CHN}(0.034)$ \\
\hline 11 & SWE (0.326) & SWE (0.594) & $\operatorname{ESP}(0.028)$ & RUS (0.029) & RUS (0.333) & ZAF $(0.030)$ & RUS (0.587) & ARG (0.033) \\
\hline 12 & CHE (0.326) & CHE (0.594) & RUS (0.025) & ARG $(0.025)$ & NET (0.326) & $\operatorname{ESP}(0.028)$ & NET (0.584) & $\operatorname{ESP}(0.027)$ \\
\hline 13 & RUS (0.319) & RUS (0.592) & NET (0.022) & NOR (0.022) & NOR $(0.326)$ & ITA (0.025) & NOR (0.584) & RUS (0.023) \\
\hline 14 & $\operatorname{ITA}(0.319)$ & ITA (0.592) & BEL (0.020) & $\operatorname{ESP}(0.021)$ & NZL (0.319) & SWE (0.021) & NZL (0.579) & NOR (0.023) \\
\hline 15 & ZAF (0.313) & ZAF $(0.587)$ & $\operatorname{MEX}(0.018)$ & NET (0.021) & JPN (0.319) & JPN (0.021) & JPN (0.579) & SWE (0.019) \\
\hline 16 & NOR (0.299) & NOR (0.584) & ITA (0.015) & CHE $(0.020)$ & ZAF $(0.311)$ & ARG (0.020) & ZAF (0.571) & NET (0.015) \\
\hline 17 & NZL (0.278) & NZL (0.577) & NOR (0.014) & SWE (0.018) & $\mathrm{CHN}(0.311)$ & $\operatorname{RUS}(0.016)$ & AUT (0.571) & BRL (0.015) \\
\hline 18 & ARG (0.278) & ARG $(0.575)$ & SWE (0.014) & BRL (0.016) & AUT (0.289) & SVK (0.015) & CHN (0.571) & $\operatorname{ZAF}(0.014)$ \\
\hline 19 & AUT (0.271) & AUT (0.573) & ZAF (0.014) & BEL (0.014) & $\mathrm{CHL}(0.281)$ & NOR (0.014) & POL $(0.566)$ & BEL (0.013) \\
\hline 20 & NET (0.271) & NET (0.573) & CHE (0.011) & ZAF (0.013) & POL $(0.281)$ & AUT (0.011) & CHL (0.566) & $\mathrm{CHL}(0.013)$ \\
\hline
\end{tabular}

Country name abbreviations: ARG (Argentina), AUT (Austria), AUS (Australia), BEL (Belgium), BRL (Brazil), CAN (Canada), CHE (Switzerland), CHL (Chile), CHN (China), ESP (Spain), FIN (Finland), FRA (France), GER (Germany), IND (India), ITA (Italy), JPN (Japan), MEX (Mexico), NLD (Netherlands), NOR (Norway), NZL (New Zealand), POL (Poland), POR (Portugal), RUS (Russia), SVK (Slovakia), SWE (Sweden), THA (Thailand), TUR (Turkey), UK (United Kingdom), USA (United States) and ZAF (South Africa).

chemical sciences; Earth and related environmental sciences; and biological sciences.

Earth and related environmental sciences and the biological sciences account for the largest parts in natural sciences in our data set: 32870 articles in Earth and related environmental sciences and 31561 articles in the biological sciences (Table 8).

In the two fields, the proportion of multi-countries articles grew steadily from 1998 to 2015 . The proportion increased from 27.7 to $48.0 \%$ in Earth and related environmental sciences and from 23.8 to $42.6 \%$ in the biological sciences.

The United States occupied the highest rank in all types of centrality measures (Table 10). The United Kingdom, Germany, France and Australia also, in general, ranked high across the indicators.

Earth and related environmental sciences and the biological sciences show similar patterns in the development of their networks (Figs. 4, 5). In both fields, the size and scale of the networks increased. The networks in 1998 and 2000 show a star-like graph centred on the
United States, while in later years, European countries, Australia and New Zealand started appearing in the networks, making the network more complex. The United Kingdom and Germany became relatively important nodes by increasingly having more connected nodes over time. At the start of the period, each of them was connected to the United States at the periphery of the network but they later became sub-cores that bridged the United States and other nodes located at the periphery.

\section{Conclusions}

Antarctic research demands a high level of collaboration on the account of the difficulty and expense of working in the region. We investigated this by looking at published journal articles, which are one of the products of research.

We found that during 1998-2015, the proportion of multi-countries articles increased from 23.0 to $33.2 \%$ in Antarctic research, making the network of Antarctic research larger and more complex. While the United 

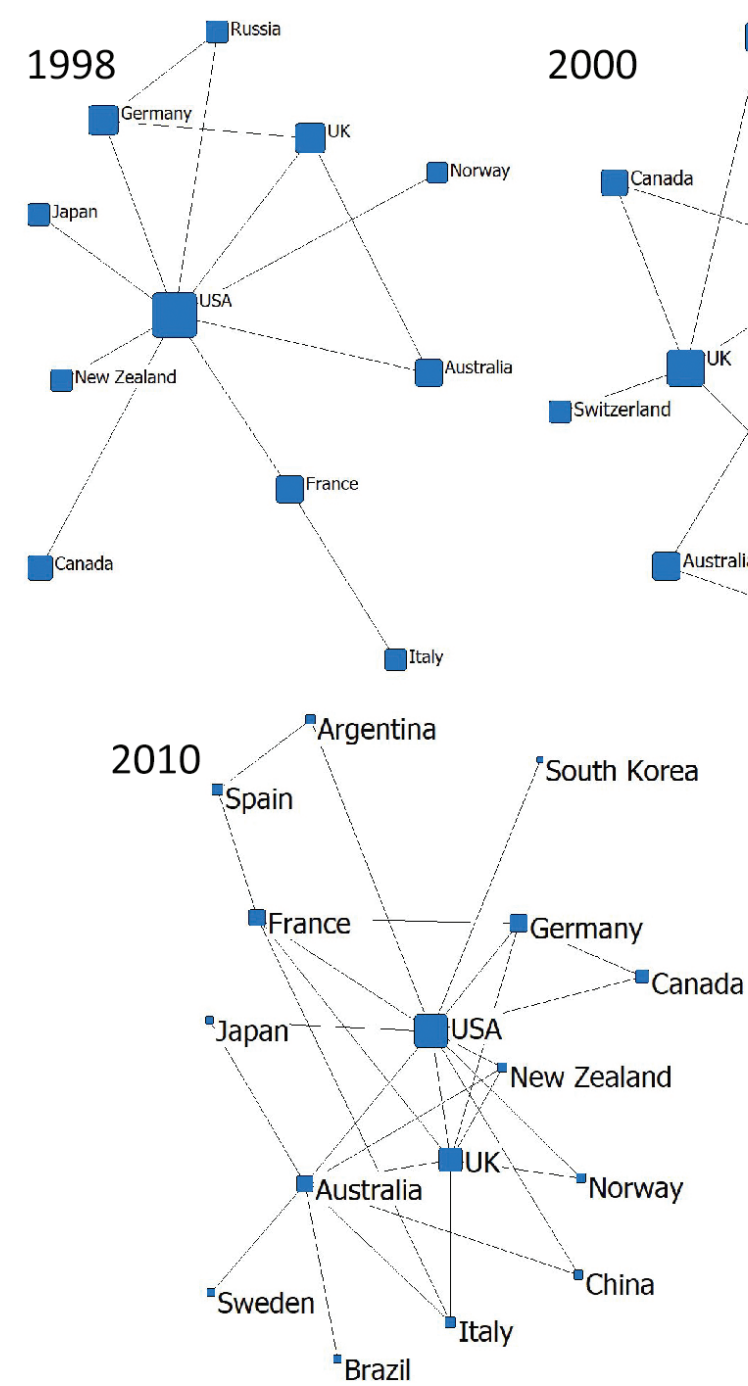
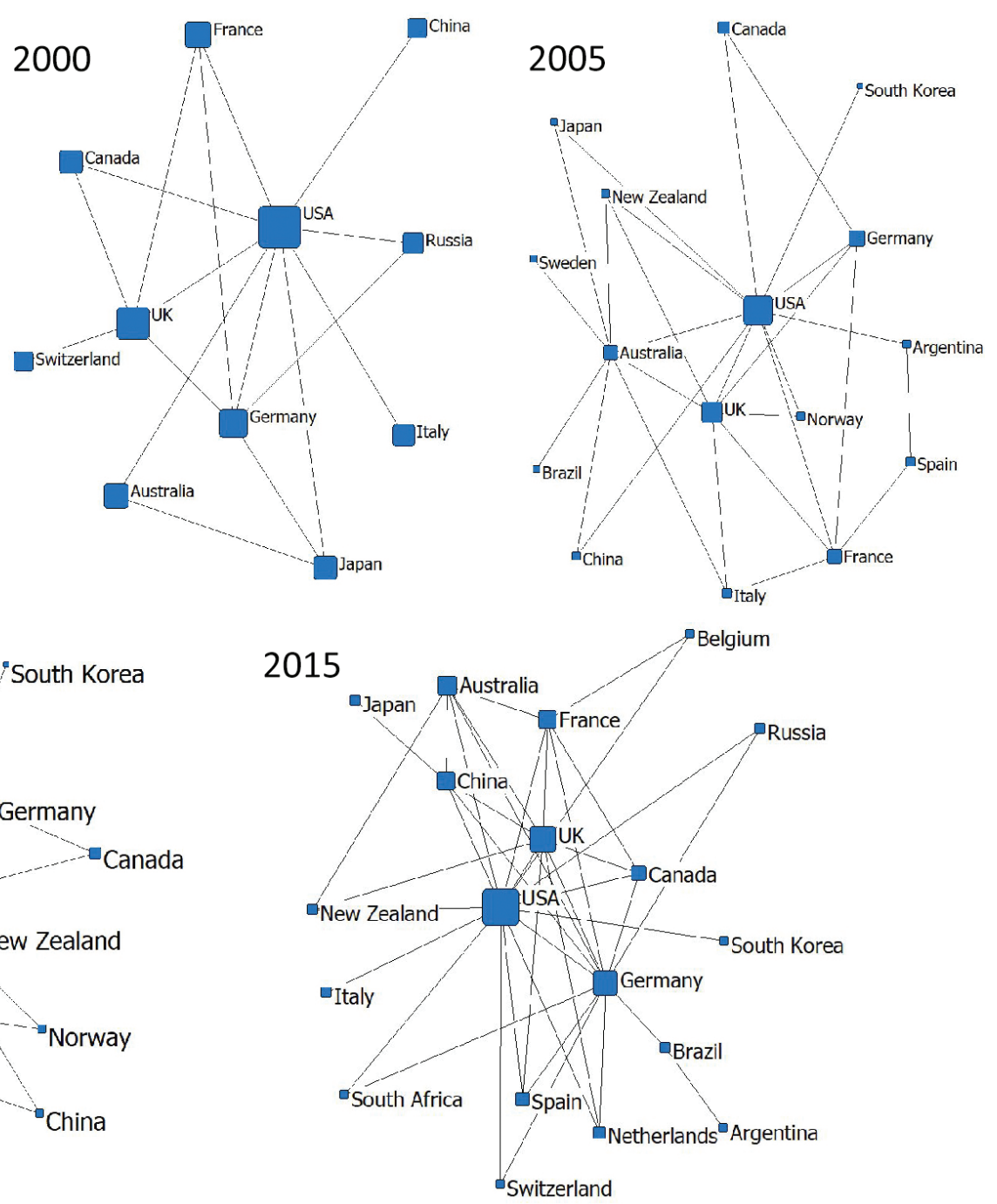

Fig. 4 Changes in the international collaboration in Earth and related environmental sciences. Only links with a frequency of 10 or higher are presented. Node sizes represent the number of links connected to each node.

States was continuously been located at the centre of the network drawn by the multi-countries articles, its percentage decreased over time. Meanwhile, the contributions of some emerging countries, such as China, Turkey, Brazil and South Korea, rose. Articles in the natural sciences were the most numerous compared with other academic fields. The comparatively small number of social science and humanities articles is to be expected for a continent peopled by small numbers of researchers and support personnel, most of whom are on the continent or the surrounding waters for short periods of fieldwork or research cruises. Subfields within the natural sciences, such as Earth studies and related environmental and biological sciences, had the highest multinational collaborative research engagement, judging by journal articles. Sweden, Belgium and the Netherlands did not produce a high percentage of academic contributions but were still notable for their international collaborative research. A topic for future study would be to see if there are important geographically driven collaborations by certain countries. For example, many countries have bases on King George Island in the South Shetlands; do these countries work together or not? Other countries have bases in reasonably close proximity on the northern part of the Antarctic Peninsula; do they work together? Also, in the McMurdo region, are the Americans, New Zealanders and Italians working together more than with other international colleagues?

Additional studies will be necessary to assess whether multinational collaboration leads to better articles (as measured, e.g., by citations) and to examine the much larger question of the impact of international 

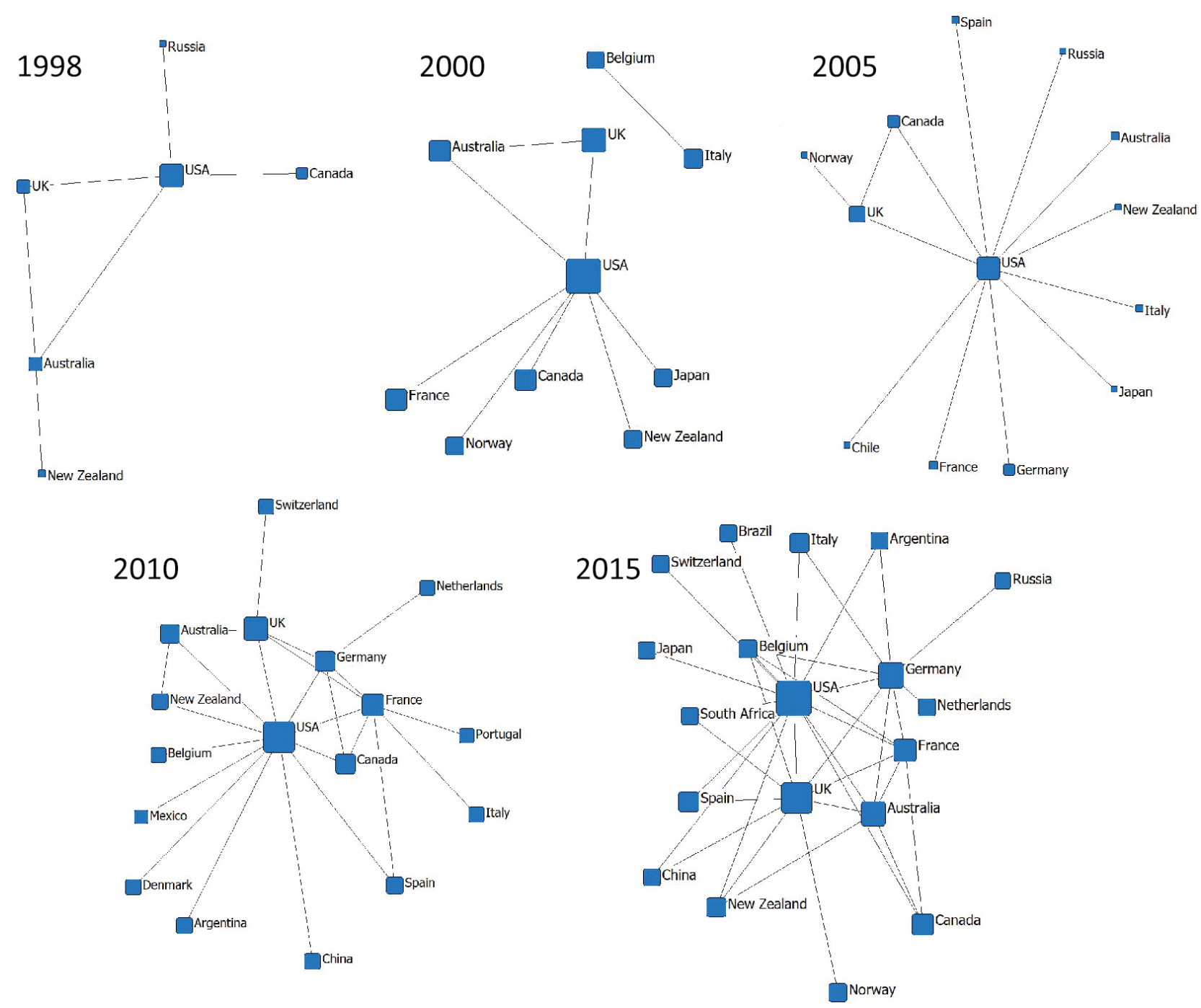

Fig. 5 Changes in the international collaboration in the biological sciences. Only the links with a frequency of 10 or higher are presented. Node sizes represent the number of links connected to each node.

collaborative research on the scientific community and society at large. Although these questions have yet to be answered, we believe that to enhance achievements in Antarctic research-which will benefit humankind globally-responsible organizations need to further encourage international collaborative research and aggressively develop and implement programmes that support collaboration.

\section{Acknowledgements}

The first draft version of this study was presented at the 63rd Annual North American Meeting of the Regional Science Association International, Minneapolis, MN, 9-12 November 2016. The authors would particularly like to thank the conference's organizers as well as the conference's attendees for the great conversation and useful discussions. The authors also thank the reviewers for their excellent comments on earlier versions of the manuscript.

\section{Disclosure statement}

The authors report no conflict of interest.

\section{Funding}

This work was supported by the Korea Institute of Ocean Science and Technology (a study on the Integrated Management of Marine Space, grant no. PE99843). 


\section{References}

Abbasi A., Hossain L. \& Leydesdorff L. 2012. Betweenness centrality as a driver of preferential attachment in the evolution of research collaboration networks. Journal of Informetrics 6, 403-412, doi: 10.1016/j.joi.2012.01.002.

Aksnes D. \& Hessen D. 2009. The structure and development of polar research (1981-2007): a publication-based approach. Arctic, Antarctic, and Alpine Research 41, 155-163, doi: 10.1657/1938-4246-41.2.155.

Barabási A.L., Jeong H., Néda Z., Ravasz E., Schubert A. \& Vicsek T. 2002. Evolution of the social network of scientific collaborations. Physica A: Statistical Mechanics and Its Applications 311, 590-614, doi: 10.1016/S0378-4371(02)00736-7

Boardman P.C. 2009. Government centrality to university-industry interactions: university research centers and the industry involvement of academic researchers. Research Policy 38, 1505-1516, doi: 10.1016/j.respol.2009.09.008.

Borrett S.R., Moody J. \& Edelmann A. 2014. The rise of network ecology: maps of the topic diversity and scientific collaboration. Ecological Modelling 293, 111-127, doi: 10.1016/j.ecolmodel.2014.02.019.

Boyd P.W., Watson A.J., Law C.S., Abraham E.R., Trull T., Murdoch R., Bakker D.C.E., Bowie A.R., Buesseler K.O., Chang H., Charette M., Croot P., Downing K., Frew R., Gall M., Hadfield M., Hall J., Harvey M., Jameson G., LaRoche J., Liddicoat M., Ling R., Maldonado M.T., McKay R.M., Nodder S., Pickmere S., Pridmore R., Rintoul S., Safi K., Sutton P., Strzepek R., Tanneberger K., Turner S., Waite A. \& Zeldis J. 2000. A mesoscale phytoplankton bloom in the polar Southern Ocean stimulated by iron fertilization. Nature 407, 695-702, doi: 10.1038/35037500.

Bray D. 2016. The geopolitics of Antarctic governance: sovereignty and strategic denial in Australia's Antarctic policy. Australian Journal of International Affairs 70, 256-274, doi: 10.1080/10357718.2015.1135871.

Chown S.L., Hughes J.E.L., Barnes J., Barrett P.J.J., Bergstrom D.M.M., Convey P., Cowan D.A., Crosbie K., Dyer G., Frenot Y., Grant S.M., Herr D., Kennicutt M.C. II, Lamers M., Murray A., Possingham H.P., Reid K., Riddle M.J., Ryan P.G., Sanson L., Shaw J.D., Sparrow M.D., Summerhayes C., Terauds A. \& Wall D.H. 2012. Challenges to the future conservation of the Antarctic. Science 337, 158-159, doi: 10.1017/S0032247411000763.

Dastidar P.G. \& Ramachandran S. 2008. Intellectual structure of Antarctic science: a 25-years analysis. Scientometrics 77, 389-414, doi: 10.1007/s11192-007-1947-x.

Elzinga A. 2009. Through the lens of the Polar Years: changing characteristics of polar research in historical perspective. Polar Record 45, 313-336, doi: 10.1017/ S0032247409008316.

Erb K.A. 2011. International collaboration in the Antarctic for global science. In P.A. Berkman et al. (eds.): Science diplomacy: Antarctica, science, and the governance of international spaces. Pp. 265-270. Washington, DC: Smithsonian Institution Scholarly Press.

Fogg G.E. 1992. A history of Antarctic science. New York: Cambridge University Press.
Freeman L.C. 1978. Centrality in social networks conceptual clarification. Social Networks 179, 215-239, doi: 10.1016/0378-8733(78)90021-7

Geissler P.W. \& Kelly A.H. 2016. A home for science: the life and times of tropical and polar field stations. Social Studies of Science 46, 797-808, doi: 10.1177/0306312716680767.

Grossman B.J.W. \& Erdo P. 2002. Patterns of collaboration in mathematical research. SIAM News 35, 14-16, doi: 10.1142/S0219030302000034

Hanessian J. 1960. The Antarctic Treaty 1959. International and Comparative Law Quarterly 9, 436-480, doi: 10.1093/ iclqaj/9.3.436.

Heggie V. 2016. Higher and colder: the success and failure of boundaries in high altitude and Antarctic research stations. Social Studies of Science 46, 809-832, doi: 10.1177/0306312716636249.

Henriksen D. 2015. The rise in co-authorship in the social sciences (1980-2013). In A.A. Salah et al. (eds.): Proceedings of ISSI 2015 Istanbul: 15th International Society of Scientometrics and Informetrics Conference. Pp. 209-220. Leuven, Belgium: International Society for Scientometrics and Informetrics.

Jang D., Choi Y.J. \& Kim J.Y. 2016. Research trend analysis on international research collaboration in regard to Antarctic studies. Ocean and Polar Research 38, 209-224, doi: 10.4217/OPR.2016.38.3.209.

Katz J.S. 1994. Geographical proximity and scientific collaboration. Scientometrics 31, 31-43, doi: 10.1007/BF02018100.

Leydesdorff L. 2007. Betweenness centrality as an indicator of the interdisciplinary of scientific journals. Journal of the American Society for Information Science and Technology 58, 1303-1319, doi: 10.1002/asi.20614.

Lüdecke C. 2003. Scientific collaboration in Antarctica (1901-04): a challenge in times of political rivalry. Polar Record 39, 35-48, doi: 10.1017/s0032247402002735.

Macfarlane B., Devine E., Drake T., Gilbert A., Robinson M. \& White I. 2017. Co-authorship in the humanities and social sciences: a global view. A White Paper from Taylor \& Francis. Accessed on the internet at https:// research-information.bristol.ac.uk/en/publications/ coauthorship-in-humanities-and-the-social-sciences(81d6f2a6-d5la-47e7-8356-a35el67ecc2c).html on 24 September 2020.

NESTI Working Party (Working Party of National Experts on Science and Technology Indicators) 2007. Revised field of science and technology (FOS) classification in the Frascati manual. Paris: Organisation for Economic Co-operation and Development, Committee for Scientific and Technological Policy, Directorate for Science, Technology and Industry. Accessed on the internet at https://www.oecd.org/science/ inno/38235147.pdf on 24 September 2020.

Newman M.E.J. 2001. The structure of scientific collaboration networks. Proceedings of the National Academy of Sciences of the United States of America 98, 404-409, doi: 10.1073/ pnas.98.2.404.

O'Reilly J., Oreskes N. \& Oppenheimer M. 2012. The rapid disintegration of projections: the West Antarctic Ice Sheet and the Intergovernmental Panel on 
Climate Change. Social Studies of Science 42, 709-731, doi: $10.1177 / 0306312712448130$

Otte E. \& Rousseau R. 2002. Social network analysis: a powerful strategy, also for the information sciences. Journal of Information Science 28, 441-453, doi: 10.1177/016555150202800601.

Petrică N. 2017. Antarctica-the game of great powers' geopolitical strategies. Bulletin of the Transilvania University of Brasov. Series V. Economic Sciences 10, 215-228.

SCAR 2010. SCAR Strategic Plan 2011-2016: Antarctic science and policy advice in a changing world. Cambridge, UK: Scientific Committee on Antarctic Research.

Summerhayes C.P. 2008. International collaboration in Antarctica: the International Polar Years, the International
Geophysical Year, and the Scientific Committee on Antarctic Research. Polar Record 44, 321-334, doi: 10.1017/ S0032247408007468.

Waltman L. \& van Eck N.J. 2015. Field-normalized citation impact indicators and the choice of an appropriate counting method. Journal of Informetrics 9, 872-894, doi: 10.1016/j.joi.2015.08.001.

Wasserman S. \& Faust K. 1994. Social network analysis: methods and applications. Cambridge: Cambridge University Press.

Watts D.J. \& Strogatz S.H. 1998. Collective dynamics of "small-world" networks. Nature 393, 440-442, doi: $10.1038 / 30918$.

Wellman B. 1983. Network analysis: some basic principles. Sociological Theory 1, 155, doi: 10.2307/202050. 